\title{
Exploring the Implications of District Splitting on the Constitution and Functionality of District Service Commissions in Uganda: A Case Study of 8 Districts in Uganda
}

\author{
Aloysius Mutebi*, Xavier Nsabagasani, Fredrick Makumbi, Elizeus Rutebemberwa \\ Department of Health Policy Planning and Management, Makerere University School of Public Health, Kampala, Uganda \\ Email address: \\ amutebi@musph.ac.ug (A. Mutebi), xnsabagasani@musph.ac.ug (X. Nsabagasani), fmakumbi@musph.ac.ug (F. Makumbi) \\ ellie@musph.ac.ug (E. Rutebemberwa) \\ ${ }^{*}$ Corresponding author
}

\section{To cite this article:}

Aloysius Mutebi, Xavier Nsabagasani, Fredrick Makumbi, Elizeus Rutebemberwa. Exploring the Implications of District Splitting on the Constitution and Functionality of District Service Commissions in Uganda: A Case Study of 8 Districts in Uganda. International Journal of Health Economics and Policy. Vol. 4, No. 2, 2019, pp. 35-43. doi: 10.11648/j.hep.20190402.11

Received: February 5, 2019; Accepted: March 25, 2019; Published: April 18, 2019

\begin{abstract}
In Uganda district splitting occurs when new districts are created out of old districts using existing boundaries which usually constitute a health sub district or county boundary. The Ugandan system of local governance is based on the district as a functional unit under which there are lower local governments and administrative units that follow the devolution system of decentralisation. The aim of this study was therefore to assess issues affecting constitution, functionality and operationalization (establishment and appointment) of District Service Commission (DSCs). This was an exploratory crosssectional study that used qualitative methods about the implications of the phenomenon of district splitting (creation) in relation to constitution and functionality of the district service commissions and human resources for health management. We purposively collected data from 16 key informants based on their roles and responsibilities on the DSCs. Out of the eight districts in the study, only one district constituted a fully functional DSC while the remaining seven districts managed to constitute DSCs in a period between 6 and 12 months. This study shows that splitting negatively affected both the parent and child (new) districts in sense that they could not constitute a complete committee within the stipulated time of three months. Generally, all the districts have had challenges in constituting the DSCs of 5-7 commission committee members. Only one in the eight districts had managed to constitute a full committee within three months of post-splitting. After districts are split, majority of the DSCs especially in the child districts took over almost a year to be constituted and fully functional due to mainly lack of qualified members for example retired senior civil servants in these districts. All the eight districts had a challenge of political interference during the process of appointing the technical team, which delayed constitution of quorum of DSCs in the districts. Lack of resources to carry out most of the DSC functions was also mentioned in all districts as a major hindrance to the district councils which were responsible for appointing DSC members. The DSCs should be allowed to operate with no political interference and this can be enacted as a law by parliament.
\end{abstract}

Keywords: District Splitting, District Service Commissions, Constitution, Functionality

\section{Introduction}

Local governments are critical for effective service delivery worldwide. In Uganda, district splitting is the creation of new districts by separating the old district along existing boundaries which usually constitute a health sub district or county boundary. The local governance system in Ugandan is based on the district as a functional unit under which there are lower local governments and administrative units that follow the devolution system of decentralisation. The law in Uganda stipulates that boundaries of a district unit may be altered or new district units formed, in accordance 
with article 179 of the Constitution [1]. Uganda has a highly decentralised governance system under which the role of structures such as the district service commission (DSC) cannot be underestimated. For the newly created districts, the DSCs are supposed to be enacted or established within three months but they have always encountered political and administrative challenges while fulfilling the requirements so as to be fully operational. There are issues that affect establishment and operation of DSCs that need to be understood.

The district service commissions (DSCs) are established by the District Service Commission act enacted by parliament [2] and the DSC derives its existence from Article 198 and section 55 of the 1995 Constitution and Local Governments Act 1997 as amended 2001 respectively [1, 3]. The functions of the commission are entrenched in Article 200(1) of the constitution and section 56(1) of the Local Governments Act. The Public Service Commission under the Ministry of Public Service provides an oversight management of DSCs in terms of approving their actions, coordination and capacity building. In the Health Ministry, Public Service Commission (PSC) works closely with the Health Service Commission on matters concerning health workers recruitment at district level. The Health Service Commission (HSC) was created under Article 169 of the 1995 Constitution and its functions are stipulated in Article 170 [2]. In the Act, Parliament also prescribed the categories of Public Officers who constitute the Health Service and defined them as "Health Workers" to mean a Health Professional, Administrative, Scientific and Support Staff employed in the Public Service for efficient and effective delivery of health service in Uganda.

Human resource management (HRM), the management of work and people towards desired ends, is a fundamental activity in any organization in which human beings are employed [4]. Distribution of human resources is important in determining access to health care [5]. Uganda's government and Ministry of Health have been working together to continue supporting the health system during the years of intense reorganization of districts and localization of government resources. Decentralization allows local governments to hire staff from within the locality [6]. The Ugandan health system suffers from dual management [7]. Urban facilities and tertiary hospitals are managed centrally by the Ministry of Health, while district hospitals and health centres II, III, and IV are managed by district governments. However, many districts lack the financial and human resources for effective management of the health system. Many health professionals find it challenging or even impossible to work under such conditions, contributing to absenteeism [8].

The DSC's roles are to advertise, receive applications, short list candidates and interview, and appoint district workers using standard PSC guidelines. District Service Commissions are also responsible for monitoring performance and promotion of human resources and taking disciplinary action against workers where need arises. The constitution and functions of the DSC are defined in the LGA and the DSC guidelines. According to the guidelines provided, the DSC is supposed to include a chairperson and at least three but not more than seven members. The Chairperson is supposed to be a full time member while other members are part time. Having at least two female members on the Commission is a statutory requirement. The secretary to the Commission is supposed to be a public servant at the rank of Personnel Officer who also heads the Commission's secretariat. The posts of Secretary (Principal Personnel Officer), Personnel Officer, Assistant Records Officer, and, Office attendant have been recently established as part of the DSCs [3].

The first local government structures in Uganda were created in 1948 and were bigger entities in terms of geographical coverage and were referred to as provinces under the colonial rule arrangement. The first districts were then demarcated in 1959 (16 districts) and later increased to 17 in 1962 (first split). Though district splitting has occurred since 1959, the peak of the splits has occurred during the National Resistance Movement regime especially between 1990 and 2016 wherein the number of districts tripled from 39 districts in 1990 to 127 districts in 2016. When Uganda endorsed the decentralised system of government in 1992, splitting became more pronounced following the principle of bringing the services nearer to the people. Decentralisation has been defined as transfer of decision-making power and assignment of accountability and responsibility for results. It is accompanied by delegation of commensurate authority to individuals or units at all levels of an organization or structure even those far removed from headquarters or other centres of power. There are different schools of thought regarding the intensity of the district splitting and most zero down to political, geographical, social reasons and overwhelmingly, political interests. Most of the district creation studies have pointed at the incentives and interests of the national government - in particular the motivations of the president - in order to explain the proliferation of districts (Green, 2008; Robert, Mesharch, \& Molenaers, 2018) [11, 12]. According to government's official rationale for district splitting:

"Is to bring services nearer to the people."

"As a way of creation of jobs for the people in the locality."

"Offers correction if district leaders do not manage their district well (accountability)."

"Creating equity in terms of sharing on the national cake."

Uganda seems to have used all the three at one time in isolation but finally settled for devolution or democratic decentralisation [13]. Devolution involves the transfer of resources and power (and often, tasks) to lower level authorities which are largely or wholly independent of higher levels of government, and which are democratic in some way and to some degree [14]. The World Bank analysts have defined devolution as, "the decentralisation of resources and responsibilities without... (democratising) political reforms would have been incomplete and, probably, not conducive to 
socially effective results" [15]. Decentralisation of governance is one of the most ambitious reforms undertaken by Uganda since its independence in 1962.

District splitting remains a consistent practice over the years in Uganda especially from 1996 to date. However, there are still unanswered questions as to how this affects the structure and functionality of local government bodies. Some studies have been conducted around decentralisation and district creation but they all focused on issues of governance, leadership and management in the districts. There is very little information concerning the implications of district splitting on the constitution and functioning of the DSC.

The aim of this study was therefore to assess issues affecting constitution, functionality and operationalization (establishment and appointment) of DSCs, while also trying to understand the challenges encountered by the DSC after splitting of a district occurs and the dynamics around recruitment of staff to start work in both the parent and new districts.

\section{Materials and Methods}

\subsection{Study Design}

This was an exploratory cross-sectional study that used qualitative methods about the implications of the phenomenon of district splitting (creation) in relation to constitution and functionality of the district service commissions and human resources for health management.

\subsection{Study Sites}

This study was conducted in 8 districts of Mbarara and Ibanda from the western, Pallisa and Kibuku from the east, Lira and Dokolo from the North, Mukono and Buikwe from central and southern parts of the country. Of these districts 4 were parent districts (with original headquarters) and 4 were child districts (split away from parent within the past 5 to 10 years) selected by regions mentioned above. The selection criterion was using a poverty index, league table and years since the split occurred [16]. The parent district was older than 5 years since the split occurred while the child was less than 5 years since the split occurred.

\subsection{Study Participants}

The study participants were purposively selected due to the specific knowledge requirements and these were two from each district that included the district service commission chairperson and secretary to the commission. These two members were selected because they were the first members appointed to the DSC by district councils even in cases where the commissions took long to be functional. All in all, $16 \mathrm{KIs}$ were conducted in the 8 districts i.e. 2 per district.

\subsection{Data Collection and Analysis}

Sixteen Key informant interviews (KIs) were conducted to gather information about constitution and functionality of district service commissions after districts were split. The number of KIs was deemed sufficient when additional interviews yielded little new information [17]. The Key informant interviews were held with sixteen purposively selected district service commission employees selected from the eight participating districts. The interview guide focused on services before and after the split occurred. Data was thematically analysed and discussed in reference to some of the acclaimed reasons for creating more districts.

The KI guide was developed by the first author and discussed with the supervisors and some policy specialists before being field tested. The first author administered the guide with the help of a social scientist who also acted as the note taker.

For analysis Atlas Ti software was used to enter and make the necessary comparisons and cross examination of information to come up with findings. Data was thematically analysed and discussed in reference to some of the acclaimed reasons for creating more districts.

\subsection{Data Processing and Management}

All interviews with the members of the DSCs and Public Service Commission (PSC) were conducted in English, taperecorded, transcribed and compiled together with field notes by the first author. Two social scientists transcribed all the sixteen KIs. Latent thematic content analysis [18] was used to analyse the data. The first author with the social scientist independently reviewed and coded interviews using a deductive approach based on the key themes provided. They both discussed individual matrices with focus on differences (in coding) until agreement was reached.

\subsection{Ethical Considerations}

The study was approved by the Institutional Review Board at Makerere University School of Public Health, Uganda National Council of Science and Technology (SS 2678). Respondents were informed of the study objectives along with risks and benefits of their participation. Interviews were conducted only after receiving written informed consent from participants. Confidentiality of information collected was ensured by not writing names of respondents on data collection forms and storing data on password protected computers.

\section{Results}

There were three key overarching findings of the study: (1) The splitting negatively affected both the parent and child (new) districts in sense that they could not constitute a complete committee. (2) Almost all split districts continued to rely on DSCs from neighbouring districts for the start. (3) Majority of the split districts took long before getting fully functional DSCs.

\subsection{Constitution of DSCs in Both the Parent and Child Districts}

A district service commission is supposed to consist of a 
chairperson, a secretary and such other members as a district council shall determine, at least one of whom shall represent urban authorities and all of whom shall be appointed by the district council on the recommendation of the district executive committee with the approval of the Public Service Commission. Members of a district service commission hold office for a period of four years, and are eligible for reappointment for one further term. District service commissions are required by law to have at least 7 members of whom two are permanent members i.e. a chairperson and a secretary, then a representative of disabled persons in the district, a member representing urban authorities and overall a balance between males and females.

\subsection{The Effect of Splitting on the Constitution of the DSC}

This study shows that splitting negatively affected both the parent and child (new) districts in sense that they could not constitute a complete committee within the stipulated time of three months. According to what was reported in the interviews, the process of appointing and operationalization of DSCs started after a child (new) district had been approved by parliament. Immediately, the Ministry of Finance (MOF) would naturally allocate indicative figures for a budget for the new district to start on the planning processes. The Ministry of local government would officially inform the chief administrative officer (CAO) of the parent district (original district) to identify some staff to be posted on secondment to the new district to start it off.

"In our district the Assistant Chief Administrative Officer (ACAO) was immediately appointed to take over leadership and management as acting CAO in the new district. He had the experience of working as an ACAO for 5 years and therefore knew all the processes and requirements by the local government. He was actually seconded by his previous boss (CAO) and later interviewed and appointed by the DSC (DSC Member 1).

This split kind of affected the number of DCS members available at the origin and destination. Out of the eight districts that were studied, only one parent district was able to constitute a DSC within the mandatory period of within three months as provided for in the Local Government Act. Then seven districts took more than twice the stipulated time to constitute DSCs but they all managed to constitute them within a period of up to one year.

Table 1. District status and period of constituting DSCs.

\begin{tabular}{lll}
\hline District & Status (child or parent) & $\begin{array}{l}\text { Period taken to } \\
\text { constitute DSC }\end{array}$ \\
\hline 1. BUIKWE & CHILD & 10 onths \\
2. DOKOLO & CHILD & 4 months \\
3. IBANDA & CHILD & 8 months \\
4. KIBUKU & CHILD & 12 onths \\
5. LIRA & PARENT & 9 months \\
6. MBARARA & PARENT & 5 months \\
7. MUKONO & PARENT & 3 months \\
8. PALLISA & PARENT & 6 months \\
\hline
\end{tabular}

Findings showed a lot of political interference and interests by district councillors who tried to influence the process of recruitment of DSC members by bringing in people with either their political affiliation or their relatives.

Several retired civil servants were seconded by politicians but they didn't qualify because they lacked the HSC qualifications. We decided to use a DSC of a neighbouring district because it was complete and had good working relations with our child district. The neighbouring district DSC played the lead role but I as DSC chairperson of child district and my secretary, we both sat in and participated in the selection (DSC Chair 3).

For example in our district the district executive committee came up with some names that had been recommended by the district council for approval to be short listed for interviews for members of the DSC but all were rejected because they did not qualify. These types of rejections would stall the process for months before another list would be forwarded for consideration (DSC Chair 11).

It's clearly stated in the constitution "A member of Parliament, a local government council or an executive body of a political party or political organisation or a public officer shall not be appointed a member of a district service commission". In addition the local government act also adds that DSC members must be people that have served at senior level (DSC chair 1).

Therefore, most of the delays were as a result of district councils recommending people on political grounds when even they did not have the required qualifications for DSC membership. The district executive committees and DSCs kept rejecting these people without the requirements until they got the right persons for interview. These types of delays went on for some time and could take even up to a year or two years.

Let me tell you this, do you know that some of the councillors despite knowing the required qualifications kept saying they wanted their people born in their districts using the term "Son of the soil"? (DSC Chair 4)

The DSC eligibility qualifications were hard to fulfil in some of the districts due to various reasons. The requirement of having been a retired senior civil servant at the level of a head of department was a hard qualification. Majority of the districts had retired civil servants but they had retired without attaining the required level. Meanwhile other districts that had enough qualified persons also had challenges of selecting the best members. Some council members fronted people from their political parties or relatives or friends. Many times the selection took long because of disagreements between council members. The solution to these selection struggles was in most cases solved by the HSC representatives on the committees because of their independent status on the committees.

The PSC and HSC did a good thing to send a representative of their committees because these people have been very professional, they do not take sides during the selection discussions and they do not compromise with politics of the district leaders or council. This has really helped when appointing the genuine committee members 


\section{(DSC Secretary 7).}

In some of the districts, religious leaders complained when they did not see any member from their religion on the committees. This was became a problem and subsequently delayed the selection of members as the councils tried to take into consideration the various requests by different district stakeholders. The gender balance is clearly stated in the local government act as a requirement that there should be at least two women on the committee. This also made the selection very hard because retired women senior civil servants were very hard to find in most of the districts. Because of this gender requirement, most of the districts had to borrow the services of women committee members from neighbouring districts so as to make quorum.

\subsection{Factors Affecting Functionality of DSCs in Both Parent and Child Districts}

The process of setting up DSCs by law is supposed to be done within three months but due to different problems encountered by different districts the majority took more than three months up to twelve months. Only one district among the eight districts was constituted within three months and became fully functional while the remaining seven districts took between four months to one year before they could become fully functional due to challenges of constituting quorum.

"In our case when the child district was created, we in the parent district were badly affected because it took us almost one and a half years to fill-in the empty vacancies on the DSC despite us being the parent district. We had only three members i.e. a chairperson, secretary and a female member for all that time. Meanwhile the child district managed to constitute a DSC in six months (DSC Member 2).

Delays in the constitution of DSCs also affected their functionality. District service commissions could not do business with less than four members on the committee. The lack of quorum affected the recruitment processes in both the parent and child districts after the split occurred. In most cases the parent district lost a number of DSC members to the child district and therefore no longer had enough members to form quorum to enable meetings and recruitment take place though in many cases the parent districts were quick to fill the gaps compare to child districts.

Our district took almost 14 months before it could become fully functional and this was because most of the people seconded by the district council did not fulfil the requirements by PSC to become members of DSCs. There was a lot of politics involved at council level which in a way blocked people with the right qualifications just because they were not in the ruling party (Chairperson 3).

The child districts in most cases had to start from nothing or started with very few DSC members from the parent district and then advertise for more members from their districts. In both cases the majority of DSCs could not form forum and therefore used DSCs of neighbouring districts to interview applicants and recruit the successful ones.

Even after the split we did not use the parent district DSC because of the issues that arose after the split occurred. We preferred using another district's DSC even if they were further away. This is because of the way they treated us during the sharing of movable assets. They damped all the spoilt or damaged assets in our child district e.g. cars that could not move (Secretary 1).

The staffs that were seconded by the parent district (CAO) to kick start the child district in most cases were not experienced enough or did not have the required qualifications for those positions. Meanwhile district councils wanted them to be confirmed in these positions because in most cases they were born in the district. This created a lot of challenges to the DSCs across all districts.

\subsection{Challenges Encountered by DSCs of Both Parent and Child Districts After District Splitting Occurs}

Generally all the districts have had challenges when it came to constituting the DSCs i.e. appointing the 5-7 members of the committee. Among the 8 districts it's only one district that managed to constitute a full committee within the required three months after splitting.

In our district we were very lucky because we had a big number of retired senior civil servants to choose from and therefore replaced the 2 members who joined the child district within only one month (Chairperson4).

Districts like Mukono have quite a number of retired senior servants because of their proximity to the Kampala capital city and neighbouring Wakiso district which house majority of the civil servants (Chairperson6).

After one year of splitting 6 out of the 8 districts had fully functional DSCs while the remaining 2 districts also managed to get functional DSCs in the following 2 months which was slightly over one year.

Because of the delays in constituting fully functional DSCS in the split districts, many civil servants remained in acting positions for more than a year whereas they should have worked for six months and thereafter they should have been interviewed for the jobs (secretary 3).

All the 8 districts delayed to advertise, interview and recruit health workers due to various factors. The most common problem contributing to the delay was late constitution of DSCs which was also as a result of few members in the districts that fulfilled the HSC qualification requirements. Most councils preferred people that were born in their respective districts and not from other districts while some council members preferred people with the same political affiliation even when they did not fulfil the requirements. It took long for the majority of DSCs to be fully constituted and functional.

In our district potential members seconded by the district council were rejected on more than one occasion because they did not fulfil the required qualifications. This happened because of political interference and influence by some councillors who fronted their relatives and friends (secretary 4).

The DSC is composed of qualified members and duly constituted but because of the manner in which it is 
appointed, political influence sometime found its way into the recruitment process, sometimes resulting into recruitment of weak candidates (Secretary 4).

Even we in the parent district were affected by the split because the restructuring took some time and some members were not happy with the whole process (Chairperson 6).

All the child districts had challenges with physical infrastructure in terms of lack of offices to house the DCS offices and officers. Even when they managed to secure space, there was lack of appropriate furniture and the basic utilities like water and electricity. In the absence of welldeveloped social infrastructure, it became very difficult to attract qualified members of the DSCs that were critical in the management DSCs.

We were accommodated in an improvised container for almost one year before allocating us office space in one of the new administration blocks (Secretary 5).

The child districts in most cases lacked funds to help with facilitation of DSC members which also affected their moral and performance. Many times they had to reallocate funds from other activities so as to facilitate the DSC members while implementing their activities. Lack of funds also affects parent districts in a way because they cannot conduct recruitment whenever need arises.

Another fact is that staffs were seconded from the parent districts by CAO of the parent district to come and start off work in the child district and indeed some were already working in the child district, therefore the district leadership did not consider it urgent to advertise, interview and recruit staff. They even never prioritised DSC activities when it came to allocation of funds (Secretary 12).

Funds are always scarce because the allocations to districts remained the same, there was no increase in funding from Ministry of finance. Ministry of finance only devised a way of sharing the original resources between the parent and child districts with no increment which created shortages in many departments health inclusive (Secretary 15).

\section{Discussion}

The overarching assumption for district splitting under a decentralised system is that districts are the functional unit under which all lower local governments and administrative units operate. District service commissions are responsible for appointing staff at all levels to handle technical work in the districts but there is a long gestation period in constitution and functionalising of DSCs. The local capacity in terms of personnel, funding and infrastructure and other interests affects the pace and implementation of tasks by DSCs. The requirements for being a member of the DSC are also seen as a challenge when it comes to constituting a DSC, which leaves a question of whether these qualifications are realistic. There is need to address these gaps so that DSCs are constituted within the stipulated time and become functional, and then district systems can operate effectively and efficiently with fewer challenges.

Major findings from this study showed that constitution of
DSCs was a big problem in most of the districts due to lack of people with the required qualifications with only one district out of the eight districts having constituted a DSC within the required three months. A study done in Luweero district also showed that their DSC was constituted within the required three months period but the processes were rushed and because of the manner in which the DSC was appointed, political influence sometimes found its way into the recruitment process, resulting into recruitment of some weak candidates that were less qualified [19].

Based on findings from this study, functionality of DSCs depended on how soon the DSCs could appoint members that raised quorum i.e. at least four qualified members that included a chairman, secretary and two other members. Majority of the DSCs had only two to three members thus falling short of the required quorum of at least four members. This was also the case in other districts like Lira and Apac which also had less than four members and therefore relied on the DSC of Gulu for almost a year before filling in all positions on their DSCs but surprisingly the child district of Dokolo that broke away from Lira constituted a DSC within three months [20].

The study found that though the parent districts already have the infrastructure in place, they are affected by the budget cuts that come as a result of sharing the available resources between the parent and child districts. Both parent and child districts were found to have few sources of income that could not allow for payment of any developmental projects. The same findings were in another study that mentioned shortage of funds for development hence leaving the claim of "new districts" to improve service delivery in a quandary [21, 22].

The child districts need a lot of money as they try to set up infrastructure and the basic systems in place but the money is too little to enable them do a substantive job. It was observed that without sufficient revenue to create and sustain the new district, the first casualty has often been social services. These findings concurred with findings from another study which found that majority of the districts could not afford making any additions to their infrastructure due to lack of funds [22].

The study findings showed that DSC constitution and functionality is grossly affected by lack of funds. Its constitution requires interviews to appoint DSC members, office space and their facilitation to start work but to lack or little funds, the district councils are limited in terms of executing their responsibilities of appointing DSCs in place. A study conducted in Uganda mentioned that financial constraints contributed to the poor performance of newly created districts and also affected some of the older districts $[10,23]$.

The president of the Uganda Local Government Association (ULGA), which brings together district chairpersons, chief administrative officers and mayors, admits that new districts cannot afford to deliver services, and he urges government to stop creating districts. "We are not against the creation of districts per say, but there should 
be matching finance resources when districts are created, "he says. The chairman of Agago district, one of the 25 new districts formed in 2010 says that without money, districts cannot even attract the basic professional staff needed to sustain services. "There should be money to pay workers to provide services. There are new districts that should not have been created," he charges [21]. "Some do not even have the required population as required in the local government laws. They were created just because people made noise [24]." "As leaders of local government we are not happy with the central government in the way it is financing the districts. The percentage of grants to districts has stagnated," he said [25]. It was also mentioned that most of the potential sources of revenue were taken over by Uganda Revenue Authority (URA) and therefore districts were left with almost no sources of revenue [26].

The study also found that when it came to constituting DSCs, most parent districts took shorter periods of between 3 to 6 months to raise quorum and become fully functional while majority of the child districts took over six months to constitute their DSCs. However, there was a case where the parent district took much longer than the child district to constitute a fully functional DSC because the child district had more senior retired civil servants and also had less political influence than the parent district. In other studies in Luweero district (parent) the DSC took only two months to be constituted and to be fully functional while Nakaseke district (child) took over twelve months to be constituted with a fully functional DSC due to political interference [19].

\section{Limitations of the Study}

The key informant interviews were limited to the DSC chairpersons and secretaries because they are the permanent members on the DSCs and they are the first people appointed on the DSC. Most of the other members of the DSC joined at a later stage after a lot of administrative decisions had taken place regarding the constitution and functionality. Though the DSC chairpersons, and their respective secretaries were very knowledgeable about district creation and new almost everything that took place during and after the districts split, there was a possibility of other DSC members knowing giving some information beyond the chairperson and secretary especially regarding the gender and disability composition.

\section{Conclusions and Recommendations}

After districts are split, majority of the DSCs especially in the child districts took over almost a year to be constituted and fully functional due to mainly lack of qualified members i.e. retired senior civil servants in these districts. Most of those born in these districts tend to retire and reside in and around cities like Kampala. There was also the problem of political interference in the appointment of members which delayed constitution of quorum in some districts. Lack of resources to carry out most of the DSC functions was also mentioned in all districts as a major hindrance. However, in some cases some of the child districts received some funds from donor projects which were used to support some of the DSC functions and operations. The study concludes that the DSCs operate in a political environment with safeguards against political influence but it is insufficient, yet they manage one of the most sensitive components of decentralisation. It is therefore, recommended that the institutional and legal position of the DSC be safeguarded from political influence peddling. At least two members of the PSC should be part of the selection and interview process of the DSCs to minimise political influence by district councils. The Public Service Commission (PSC) representatives should make the final judgement on the best candidates. The PSC guidelines on who qualifies should strictly be implemented so as to avoid bending the laws by appointing people that are less qualified and this could be better handled by PSC members and not district councils.

\section{Ethical Approval and Consent to Participate}

This study is part of a Phd research protocol that was registered with Makerere University School of Public Health Research Ethics Committee (reference number HDREC 140) and the Uganda National Council for Science and Technology (reference number SS 2678). Written informed consent was sought from all respondent who participated in this study and all information was protected and kept confidential. No videos and photographs of the respondents were taken and there was no risk to the human subjects participating in the study.

\section{Consent for Publication}

Consent to publish the findings of the study was obtained at the point of seeking consent to participate. The participants' confidentiality and anonymity while reporting was assured.

\section{Disclaimer}

The contents of the publication are solely the responsibility of the authors and do not necessarily reflect the views of any of the authors' institutions of affiliation.

\section{Availability of Data and Materials}

The data used to undertake this study is safely stored by the Principal Investigator at Makerere University School of Public Health. The same data is freely available on request through the first author of this paper.

\section{Funding}

The study was mainly funded by the Principal Investigator 
(main author) with some additional funding for tuition and the publication process of this paper from Makerere University School of Public Health.

\section{Paper Context}

In Uganda district splitting has really intensified during the past 20 years. In 2000 Uganda had 56 districts but after 10 years i.e. by 2010 the number of districts had double to 112 . Currently another 10 districts have been created within 8 years. Little is known about what happens to district service commissions after the splits occur whereas these are responsible for identifying and recruiting human resources at the district. This article explores how district service commissions are constituted and made functional after the split occurs.

\section{Acknowledgements}

Special thanks to the supervisors Prof Elizeus Rutebemberwa, Prof Fredrick Makumbi and a review (Dr Xavier Nsabagasani) plus the $\mathrm{PhD}$ forum at MakSPH. We are thankful to the participants, data collectors and enterers, and the district service commissions from the districts of Buikwe, Dokolo, Ibanda, Kibuku, Lira, Mbarara, Mukono, Pallisa for their time during data collection.

\section{Conflict of Interest}

The authors declare that they have no conflict of interests

\section{Authors' Contributions}

AM led data collection, analysis and the writing of the manuscript with the contribution from all authors. $\mathrm{XN}$ participated in conceiving and reviewing the study, FM participated in reviewing and ER provided general guidance and participated in drafting and reviewing the manuscript.

\section{References}

[1] Uganda government, 'Local Governments Act 1997 | Uganda Legal Information Institute', 1997. [Online]. Available: https://ulii.org/ug/legislation/consolidated-act/243. [Accessed: 22-Jan-2018].

[2] Government of Uganda, 'THE LOCAL GOVERNMENTS (AMENDMENT) ACT, 2005', 2005.

[3] Ministry of Local government, 'Constitution of the Republic of Uganda, 1995 | Uganda Legal Information Institute', Constitution of the Republic of Uganda, 1995, 1995. [Online]. Available: https://ulii.org/ug/legislation/consolidated-act/0. [Accessed: 20-Feb-2018].

[4] R. J. Thomas, 'What is Human Resource Management?', Work Employment \& Society. 1988.

[5] H. R. Waters, 'Measuring equity in access to health care', Soc. Sci. Med., 2000.
[6] S. Wild-River, 'The role of local government in environmental and heritage management: Integrative commentary', prepared for the 2006 Australian State of the Environment Committee, 2006, 2006. .

[7] L. Paina, S. Bennett, F. Ssengooba, and D. H. Peters, 'Advancing the application of systems thinking in health: Exploring dual practice and its management in Kampala, Uganda', Health Research Policy and Systems. 2014.

[8] V. Oketcho, I. Ezati, J. Odaga, A. A. Foster, J. McMahan, and L. Muldavin, 'UGANDA ON TRACK FOR KEEPING HUMAN RESOURCES FOR HEALTH COMMITMENTS', 2015.

[9] T. Robert, K. Mesharch, and N. Molenaers, 'New District Creation in Uganda and Local Actors: Passive Recipients or Active Pursuers?', J. Public Adm. Gov., vol. 8, no. 2, p. 62, May 2018.

[10] E. D. Green, 'Decentralisation and conflict in Uganda Article (Accepted version) (Refereed) Decentralization and Conflict in Uganda', Conflict, Secur. Dev., vol. 8, no. 4, pp. 427-450, 2008.

[11] N. Awortwi and A. H. J. Bert Helmsing, 'Behind the façade of bringing services closer to people the proclaimed and hidden intentions of the government of Uganda to create many new local government districts', Can. J. Afr. Stud., 2014.

[12] Kimuli Kasara, 'Ethnic Beachheads and Vote Buying: Explaining the Creation of New Administrative Districts in Kenya, 1963-2001', 2006. [Online]. Available: https://scholar.google.ch/citations?user=uIrzRUcAAAAJ\&hl $=$ de $\# \mathrm{~d}=$ gs_md_cita-

$\mathrm{d} \& \mathrm{p}=\& \mathrm{u}=\% 2$ Fcitations $\% 3$ Fview_op $\% 3$ Dview_citation $\% 26$ hl\%3Dde\%26user\%3DuIrzRUcAAAAJ\%26citation_for_vie w\%3DuIrzRUcAAAAJ\%3A kc bZDykSQC\%26tzom\%3D180. [Accessed: 22-Jan-2018].

[13] H. Ojambo, 'Decentralisation in Africa: A critical review of Uganda's experience', Potchefstroom Electron. Law Journal/Potchefstroomse Elektron. Regsbl., 2012.

[14] The World Bank Group, 'Administrative Decentralization', Administrative Decentralization , 2001. [Online]. Available: http://www1.worldbank.org/publicsector/decentralization/ad min.htm. [Accessed: 22-Jan-2018].

[15] R. Prud'homme, 'The dangers of decentralization', World Bank Res. Obs., 1995.

[16] GoU, 'National Development Plan (2010/11-2014/15)', 2010 .

[17] G. \& Thorogood, 'Qualitative methodology and health research', Qual. methods Heal. Res., 2009.

[18] M. Ibrahim, 'THEMATIC ANALYSIS: A CRITICAL REVIEW OF ITS PROCESS AND EVALUATION', 2012.

[19] J. Sebbowa and Joseph, 'The capacity of District Service Commissions to manage the recruitment function for Local Governments in Uganda, the case of Luweero District, (1997-2005)', 2010.

[20] journalists association, 'Challenges in Civil Service in Uganda - Fortune Of Africa - Uganda', 2011. [Online]. Available: http://fortuneofafrica.com/ug/challenges-in-civilservice-in-uganda/. [Accessed: 25-Jan-2018]. 
[21] Panelists, 'Creation of NEW DISTRICTS in Uganda: The Myths, the Truth and the Lies. | Politics of Growth and Good Governance worldwide.', 2012. [Online]. Available: http://ekimeeza.blogspot.com/2012/07/creation-of-new-inuganda-myths-truth.html. [Accessed: 20-Jan-2018].

[22] D. K. Singiza and J. de Visser, 'Chewing more than one can swallow: the creation of new districts in Uganda', Law, Democr. Dev., 2011.

[23] Onyach-Olaa Martin, 'Op-Ed: Does creation of new districts improve service delivery?', 2012. [Online]. Available: http://www.worldbank.org/en/news/opinion/2012/09/25/oped-does-creation-of-new-districts-improve-service-delivery. [Accessed: 22-Oct-2017].
[24] Uganda government, 'Physical Planning Act, 2010, 2010 Uganda Legal Information Institute', 2010. [Online]. Available: $\quad$ https://ulii.org/ug/legislation/act/2015/8-10. [Accessed: 11-Jan-2018].

[25] Kavuma Richard, 'Explainer: Local government structures in Uganda | Katine | The Guardian', 2009. [Online]. Available: https://www.theguardian.com/katine/2009/dec/14/localgovernment-explainer. [Accessed: 18-Feb-2018].

[26] Rajab Mukombozi, 'Government lacks political will to improve district funding, say local leaders - Daily Monitor', 2017. [Online]. Available: http://www.monitor.co.ug/News/National/Governmentpolitical-will-improve-district-funding-local-leaders/6883344179026-96ugtd/index.html. [Accessed: 25-Feb-2018]. 